\title{
Análise da legislação, normas e regulamentos que orientam o processo de desenvolvimento de pessoas do Instituto Federal de Mato Grosso
}

Analysis of the legislation, rules and regulations that guide the people development process of the Federal Institute of Mato Grosso

Análisis de la legislación, normas y reglamentos que orientan el proceso de desarrollo de las personas del Instituto Federal de Mato Grosso

Recebido: 04/08/2021 | Revisado: 08/08/2021 | Aceito: 10/08/2021 | Publicado: 14/08/2021

\author{
Adriana Alves da Rocha \\ ORCID: https://orcid.org/0000-0003-1132-9541 \\ Instituto Federal de Educação, Ciência e Tecnologia de Mato Grosso, Brasil \\ E-mail: adrianarocha755@gmail.com \\ Geison Jader Mello \\ ORCID: https://orcid.org/0000-0002-0991-2327 \\ Instituto Federal de Educação, Ciência e Tecnologia de Mato Grosso, Brasil \\ E-mail: geison.mello@cba.ifmt.edu.br
}

\begin{abstract}
Resumo
O Instituto Federal de Educação, Ciência e Tecnologia de Mato Grosso - IFMT é uma instituição centenária, possuindo um quadro de pessoal com uma média de 1.900 servidores, com sua visão de formação humana integral, formando pessoas para a vida e para o mundo do trabalho, com um rico processo de formação continuada e/ou desenvolvimento de pessoas ao longo da carreira. Existe dificuldade dos servidores em compreender o processo de desenvolvimento de pessoas, para corroborar com esse entendimento o artigo analisa e identifica as legislações e normativas que regulamentam esse processo. O objetivo geral do artigo foi analisar as legislações, normas e orientações que norteiam o processo de desenvolvimento de pessoas do IFMT, corroborando com o entendimento da comunidade IFMT sobre a temática. Para isso, foram necessárias algumas ações como: levantar e analisar o aparato de referencial teórico sobre a temática desenvolvimento de pessoas; identificar as legislações, regulamentos e normas que orientam o processo de formação dos servidores, explanando sobre as Políticas Nacionais de Desenvolvimento de Pessoas, normativas e regulamentos internos do IFMT. Como metodologia, iniciou-se com uma revisão bibliográfica e documental sobre a temática, sendo assim uma pesquisa qualitativa com objetivo exploratório, de natureza aplicada, utilizando como método o estudo de caso, em que foi realizada a análise de dados, descrevendo o processo de desenvolvimento de pessoas dentro da Instituição.
\end{abstract}

Palavras-chave: Desenvolvimento de pessoas; Gestão do conhecimento; Capital intelectual.

\begin{abstract}
The Federal Institute of Education, Science and Technology of Mato Grosso - IFMT is a centenary institution, with a staff of an average of 1,900 employees, with its vision of integral human education, training people for life and for the world of work, with a rich process of continuing education and/or development of people throughout their career. There is difficulty for servers to understand the process of people development, to corroborate this understanding, the article analyzes and identifies the laws and regulations that regulate this process. The general objective of the article was to analyze the legislation, norms and guidelines that guide the process of people development at the IFMT, corroborating the understanding of the IFMT community on the subject. For this, some actions were necessary, such as: surveying and analyzing the theoretical framework on the theme of people development; identifying the laws, regulations and norms that guide the process of training employees, explaining the National Policies for the Development of People, norms and internal regulations of the IFMT. As a methodology, it began with a bibliographical and documentary review on the subject, thus being a qualitative research with an exploratory objective, of an applied nature, using the case study as a method, in which data analysis was perfno ormed, describing the process of development of people within the institution.
\end{abstract}

Keywords: Developing people; Knowledge management; Intellectual capital.

\section{Resumen}

El Instituto Federal de Educación, Ciencia y Tecnología de Mato Grosso - IFMT es una institución centenaria, con una plantilla promedio de 1.900 empleados, con su visión de educación humana integral, capacitando a las personas para la vida y para el mundo del trabajo, con un rico processo de educación continua y / o desarrollo de las personas a 
lo largo de su carrera. Existe dificultad para que los servidores entiendan el proceso de desarrollo de las personas, para corroborar este entendimiento, el artículo analiza e identifica las leyes y reglamentos que regulan este proceso. El objetivo general del artículo fue analizar la legislación, normas y lineamientos que orientan el proceso de desarrollo de las personas en el IFMT, corroborando el entendimiento de la comunidad IFMT sobre el tema. Para ello fueron necesarias algunas acciones, como: plantear y analizar el marco teórico sobre el tema del desarrollo de las personas; identificar las leyes, reglamentos y normas que orientan el proceso de formación de los empleados, explicando las Políticas Nacionales para el Desarrollo de las Personas, normas y reglamentos internos de la IFMT. Como metodología, se inició con una revisión bibliográfica y documental sobre el tema, siendo así una investigación cualitativa con un objetivo exploratorio, de carácter aplicado, utilizando como método el estudio de caso, en el cual se realizó el análisis de datos, describiendo el proceso de desarrollo de las personas dentro de la institución.

Palabras clave: Desarrollo de personas; Conocimiento administrativo; Capital intelectual.

\section{Introdução}

O Instituto Federal de Educação, Ciência e Tecnologia de Mato Grosso - IFMT é uma instituição centenária, possuindo um quadro de 1.900 servidores, nos cargos técnicos administrativos e docentes, existindo assim a necessidade de organização da área de Gestão de Pessoas em promover ações que colaborem com o desenvolvimento dos servidores (IFMT, 2019).

Existe um significativo quantitativo de servidores, que se capacitam durante sua carreira, necessitando compreender o processo de formação continuada dentro da instituição, sendo esse desenvolvimento necessário para a carreira profissional, estando diretamente relacionada com a progressão funcional do servidor (Resolução n. 031, 2011).

O IFMT é uma instituição de ensino, que forma diversos servidores ao longo da carreira, havendo assim a necessidade de evidenciar as ações para que mais pessoas se profissionalizem, podendo melhorar seu desempenho profissional.

A formação continuada dos professores é decisiva para que a democratização da EPT se efetive com qualidade social, produção de conhecimentos e valorização docente, podendo resultar em uma formação do aluno que atenda, de fato, aos princípios do Ensino Médio Integrado (Silva \& Santos, 2020, p. 10).

A formação continuada dos profissionais da educação é significativa para o fortalecimento da rede de Educação Profissional e Tecnológica (EPT). Com a riqueza de capital intelectual que uma instituição de ensino tem, é preciso sistematizá-lo, fazendo assim a gestão do conhecimento. De acordo com Batista (2005, p. 88), “Gestão do Conhecimento é um processo sistemático de conectar pessoas com pessoas, e pessoas com o conhecimento de que elas precisam para agir eficazmente e criar novo conhecimento".

De acordo com IFMT (2019), a instituição tem como visão de ensino voltado para a formação humana integral, formando pessoas para o mundo do trabalho e para a vida. Para cumprir a visão de ensino do IFMT é primordial a formação continuada de seus colaboradores, pois um serviço público de qualidade precisa de pessoal capacitado e atualizado, dessa forma pode-se colaborar com a inovação, com a formação de um ser autônomo que possa corroborar com o desenvolvimento de nossa sociedade (IFMT, 2019).

As instituições públicas de ensino possuem recursos destinados à capacitação e ao desenvolvimento de pessoas, visando o aprimoramento do conhecimento de seus servidores, possibilitando capacitação/desenvolvimento ao longo de sua carreira no serviço público (Decreto n. 9.991, 2019).

O objetivo geral da pesquisa foi analisar o processo de desenvolvimento de pessoas do IFMT, corroborando com o entendimento da comunidade IFMT sobre as formações continuadas, suas legislações, normas e regulamentos que a norteiam.

A pesquisa teve como objetivos específicos: Levantar, analisar e descrever o aparato de referencial teórico sobre a temática Desenvolvimento de Pessoas; Identificar as legislações e normas do IFMT para o desenvolvimento dos servidores 
(as); e por fim, descrever o processo de organização da formação dentro do IFMT, fazendo um estudo de caso de acordo com as orientações de Gil (2009) e Pereira et al. (2018).

Existindo a possibilidade de dificuldade por parte dos servidores em compreender o processo de gestão de desenvolvimento de pessoas dentro do IFMT, o artigo analisou e descreveu a organização desse processo de desenvolvimento, fazendo uma análise qualitativa e facilitando a compreensão da comunidade IFMT sobre sua organização, procedimentos adotados pela instituição, auxiliando os servidores no entendimento sobre a temática. Foi explanando sobre as legislações e orientações como: Decreto n. 9.991 de 2019, que regulamentou a política Nacional de Desenvolvimento de Pessoas, o (IFMT, 2019) que retrata os objetivos institucionais, guiando as estratégias alinhadas a área de gestão de pessoas, a Resolução $\mathrm{n} .{ }^{\circ} 047$ de 2019, que regulamentou o processo de formação continuada dentro do IFMT e o IFMT (2020) que norteia o Plano de Desenvolvimento de Pessoas da instituição.

Como metodologia, foi realizada uma revisão bibliográfica e documental sobre a temática desenvolvimento de pessoas, gestão do conhecimento, explanando sobre as regulamentações nacionais, evidenciando suas normas e orientações sobre o processo formativo do servidor, a posteriori, a explanação sobre a gestão da formação continuada e/ou desenvolvimento de pessoas dentro do IFMT.

\section{Metodologia}

Como metodologia, foi trabalhada uma pesquisa exploratória com conteúdo familiar aos pesquisadores servidores da instituição, fazendo parte do desenvolvimento de pessoas dentro do IFMT. Dessa forma, foi aprofundado um determinado assunto ou problema, também foi realizada uma vasta pesquisa bibliográfica e documental sobre desenvolvimento de pessoas e gestão do conhecimento, sendo assim uma pesquisa-ação, em que os pesquisadores participaram do problema de pesquisa buscando colaborar com sua solução (Gil, 2008).

Trata-se de uma pesquisa de cunho qualitativo com objetivo exploratório e descritivo, trazendo dados e interpretações sobre as legislações, normas e orientações sobre a temática (Gil, 2008).

A pesquisa foi desenvolvida na forma de natureza aplicada, corroborando com o entendimento sobre o desenvolvimento de pessoas dentro do IFMT, tendo uma abordagem qualitativa para identificar as características da formação continuada dentro da Instituição. Seu desenvolvimento teve um objetivo exploratório e descritivo. Sobre o método utilizado, Pereira et al. (2018) têm a opinião de que a pesquisa qualitativa envolve uma interpretação do pesquisador, expondo assim sua opinião de determinado estudo.

Quanto aos procedimentos, é caracterizada como uma pesquisa-ação, colaborando com a solução de um problema pesquisado, neste caso corroborando entendimento dos servidores, realizando uma explanação sobre o processo de desenvolvimento dos servidores dentro do IFMT. Foi realizada uma vasta pesquisa bibliográfica e documental, explanando sobre as legislações, normas e conceitos da temática desenvolvimento de pessoas e/ou formação continuada e sobre a gestão do conhecimento, extraindo as informações de documentos impressos e eletrônicos, descrevendo, identificando e analisando seus dados (Vieira, 2010).

Também foi usado o método de estudo de caso que, de acordo com Pereira et al. (2018, p. 65) "é uma descrição e análise, a mais detalhada possível, de algum caso que apresente alguma particularidade que o torna especial". O artigo analisou e comparou de modo aprofundado e exaustivo os objetos de pesquisa, apresentando ações que poderão ser aplicadas no processo de gestão do conhecimento dentro da instituição (Pereira et al., 2018).

Segundo Gil (2009) o estudo de caso teve como objetivo definir, comparar, identificar, classificar e aprofundar um determinado tema. Os pesquisadores apresentaram as características de investigação aprofundando na temática, investigando e 
identificando o processo de desenvolvimento dentro da instituição, corroborando com os saberes da comunidade IFMT sobre o processo formativo dos servidores, sendo assim um estudo de caso.

Para o desenvolvimento da pesquisa foi realizado um levantamento bibliográfico e documental sobre a temática gestão do conhecimento e desenvolvimento de pessoas, realizando um levantamento sobre as legislações e normas que dispunham sobre o processo de capacitação dos servidores públicos federais, explanando a respeito do (i) Decreto n. 9.991 de 2019, que dispõe sobre a Política Nacional de Desenvolvimento de Pessoas, (ii) o Plano de Desenvolvimento da Instituição (2019-2023), (iii) o Plano Anual de Capacitação (IFMT, 2018), (iv) a Resolução n. 047 de 2019, que regulamenta o processo de desenvolvimento de pessoas dentro do IFMT, (v) o Plano de Desenvolvimento de Pessoas (IFMT, 2020), explanando seu conteúdo e evidenciando as normativas internas que regulamentam o desenvolvimento dos servidores da Instituição.

Como o artigo abordou apenas questões documentais e bibliográficas, não envolvendo seres humanos, não foi necessária a aprovação do Comitê de Ética na Pesquisa - CEP, o projeto que originou o recorte para esse artigo foi aprovado pelo CEP n. 4.302.648, atendendo às orientações do Conselho Nacional de Saúde (Resolução n. ${ }^{\circ}$ 510, 2016).

Por fim, verificou-se um significativo processo de desenvolvimento dos servidores dentro do IFMT, pode-se inferir que a Instituição possui um amplo capital intelectual. Assim, a pesquisa deixa como sugestão para a gestão do processo de desenvolvimento de pessoas a sistematização do capital intelectual, mapeando seus cargos e produzindo um significativo repositório de talentos, colaborando com a gestão do conhecimento dentro da Instituição, assim, esse repositório será capaz de subsidiar parte das ações de capacitação.

\section{Resultados e Discussão}

Neste capítulo apresenta-se os resultados da análise e discussão, evidenciando o processo organizativo da formação dos servidores do IFMT, explanando sobre as legislações nacionais e internas que norteiam o desenvolvimento de pessoas.

\subsection{Gestão do conhecimento}

A gestão do conhecimento é um processo no qual uma organização ou empresa organiza seu processo de gestão de pessoas. Essa temática está direcionada à organização das políticas de desenvolvimento de pessoas, criando legislações e normas que norteiam o processo de formação, o mapeamento de cargos, gerindo seu capital intelectual e trabalhando em políticas de formação ou de treinamento de pessoas, tudo isso está em consonância com os objetivos gerais da Instituição (Acquesta, 2018).

Para compreender o processo de gestão do conhecimento, apresenta-se os conceitos de Oliveira e Medeiros (2016, p. 106), para os autores o conhecimento é "uma abstração interior, pessoal, de algo que foi experimentado, vivenciado por alguém". "O conhecimento não pode ser descrito; o que se descreve é a informação". Contextualizando o conceito de conhecimento, Oliveira e Medeiros, (2016, p. 146) afirmam que o "conhecimento é a melhor fonte de obtenção de vantagem competitiva duradoura". Considera-se que o conhecimento é a informação ordenada, isto é, a informação que consiste em dados relevantes e objetivos.

A gestão do conhecimento é como uma instituição organiza seu processo de retenção e a disseminação do conhecimento, organizando de maneira eficaz, colaborando com o desempenho e/ou os objetivos institucionais. Esse tema surgiu no Brasil no final da década de 90:

A gestão do conhecimento surgiu como prática no Brasil há cerca de vinte anos, quando muitas organizações se deram conta do papel cada vez mais estratégico do conhecimento e passaram a buscar formas de gerenciá-lo de modo mais efetivo. (Acquesta, 2018, p. 02). 
Uma instituição com uma significativa organização da gestão do conhecimento desenvolve uma visão mais aprofundada do papel do conhecimento no desempenho das estratégias organizacionais, desenvolvendo ações que colaborem com o desenvolvimento das práticas, para isso é necessário fazer o mapeamento de suas especialidades, de forma a organizar um repositório de conhecimento (Acquesta, 2018).

Contextualizando sobre o papel estratégico da gestão do conhecimento Martins et al. (2017, p. 240), afirmam que "são essenciais para que as empresas mantenham a visão estratégica, cumpram com êxito sua missão e alcancem os objetivos".

Para conhecer o processo de gestão do conhecimento é preciso compreender que conhecimento é este, existem dois tipos de conhecimento de uma organização: um é o conhecimento tácito, aquele conhecimento tangível que pode ser distribuído em contato social através da prática e compartilhado através da tecnologia da informação; o outro o conhecimento intangível, aquele aprendizado adquirido pelo servidor ou funcionário da empresa, ocorre por meio da absorção do conhecimento pelo seu processo criativo ou de transformação do conhecimento já existente (Gonzalez \& Martins, 2017).

O conceito de conhecimento organizacional perpassa, sobretudo, através do entendimento de que:

O conhecimento organizacional é considerado, nos dias atuais, um ativo que, embora intangível, gera vantagem competitiva às organizações. Para Grant (1996), a vantagem competitiva é alcançada por meio do aperfeiçoamento contínuo e da inovação do processo produtivo e do produto, e o conhecimento é o recurso organizacional que permite à organização desenvolver tais atividades de melhoria e inovação. (Gonzalez \& Martins, 2017, p. 248).

Ao realizar as atividades laborais os servidores aprendem e adquirem conhecimentos, assim uma organização que possui objetivos de inovação do conhecimento necessita se organizar, valorizando seu capital intelectual, aprimorando e colaborando com seu processo de desenvolvimento.

Se o processo de aprendizagem acontece ao longo da carreira, precisa-se desenvolver espaços para aplicação desses saberes, disseminando-o. Segundo Martin et al. (2017, p. 243) os "colaboradores percebem a necessidade de retribuir o conhecimento aprendido orientando os novos colaboradores". Sendo assim, os próprios colaboradores veem a necessidade do compartilhamento de saberes, a organização necessita gerir esse capital intelectual, desenvolvendo ações que sistematize as informações produzidas e abrindo espaço para a replicação do conhecimento.

Segundo Luchesi (2012, p. 01) conhecimento é:

Conhecimento é o fato ou a condição do saber, obtido através da vivência, da experiência ou de uma associação. Todo este saber reside ou tem potencial para ser guardado na nossa mente, e/ou ser armazenado em uma organização, nos seus processos, produtos, serviços, sistemas e documentos. (Luchesi, 2012, p. 01).

Sabendo da importância do conhecimento na organização, é necessário desenvolver condições para disseminar e/ou compartilhar o conhecimento mediante a criação de uma cultura de compartilhamento de saberes, identificando assim os conhecimentos estratégicos para a organização, estabelecendo diretrizes e metodologias que organizam e protegem esse conhecimento organizacional (Luchesi, 2012).

Gozzi (2012), em sua pesquisa, relata a importância da valorização do conhecimento, e que o processo coletivo de compartilhamento de saberes colabora com a aprendizagem. Para a autora, é primordial manter o espaço de trocas de saberes, podendo ser físicos ou virtuais, estes ambientes proporcionam a construção do conhecimento.

É notável a importância de se criar e manter comunidades virtuais de aprendizagem para adultos, sem deixar que essa comunidade se esvazie, prolongando a sua existência, proporcionando um aproveitamento máximo do seu potencial cognitivo, enquanto houver o interesse pela aprendizagem e pela construção do conhecimento por parte dos indivíduos que a compõem, em torno de um tema específico que tenha motivado sua criação (Gozzi, 2012, p. 12). 
Esse processo de organização e disseminação do conhecimento contribui para o desenvolvimento das pessoas (Gozzi, 2012).

A Gestão de Pessoas é uma área estratégica de uma organização, sendo local em que é possível desenvolver ações que colaborem com esse processo de disseminação do conhecimento, com isso de forma indireta também é valorizado o conhecimento do servidor, sua formação e a forma de contribuir através do compartilhamento de saberes (Oliveira \& Medeiros, 2016).

A Figura 1 apresenta um exemplo de planejamento direcionado aos servidores do setor público.

Figura 1 - Planejamento Estratégico de Pessoas no Setor Público.

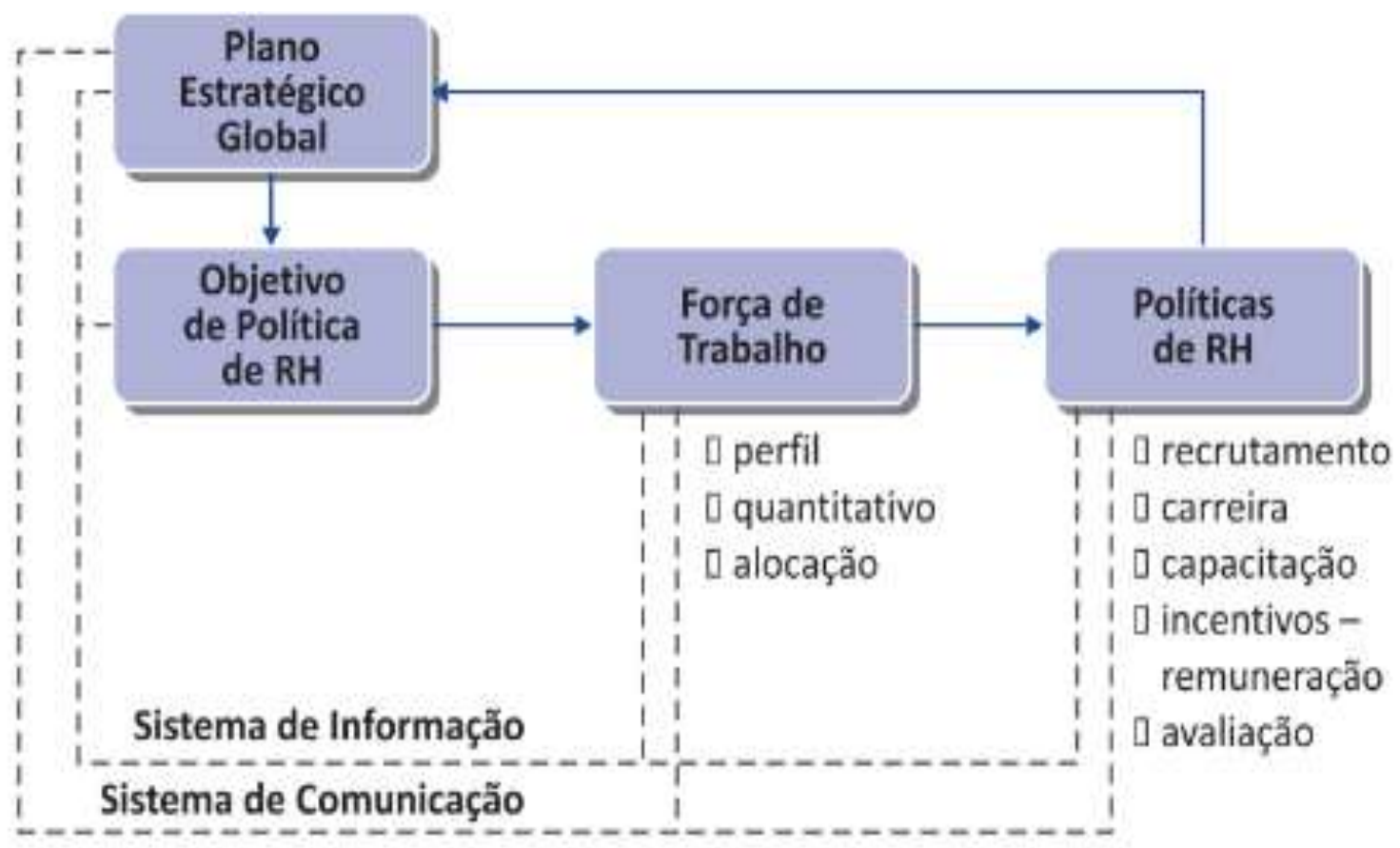

Fonte: Oliveira e Medeiros (2016, p. 29).

Sendo parte da estratégia da organização, a Gestão de Pessoas precisa de ações que promovam o desenvolvimento das pessoas com a criação de espaços de formação e de partilha do aprendizado (Oliveira \& Medeiros, 2016).

O espaço de aprendizado proporcionado pela organização é uma das ações relacionadas à gestão do conhecimento, que abre espaço e dá condições de aprendizados dentro da empresa ou instituição, e gerir esse processo é então um papel da área de Gestão de Pessoas. Para Strauhs (2012, p. 55) "o conhecimento nas organizações é proporcionar condições para criar, adquirir, organizar e processar informações estratégicas e, assim, gerar benefícios (inclusive financeiros), aumentando a competitividade".

A partir da interação entre os servidores ou funcionários é possível obter o compartilhamento de saberes, incorporando experiências, regras e cultura organizacional. Complementando o conceito dessa temática, Strauhs (2012, p. 95) afirma que "a Gestão do Conhecimento tem estreita relação com a Gestão da Inovação. Ao ser implantada, contribui fortemente para gerar ideias, registrar e compartilhar informações e conhecimentos".

Com o estudo foi possível identificar a significativa importância de trazer a gestão de conhecimento como uma estratégia organizacional, assim a área de gestão de pessoas tem um papel fundamental para a implantação e gestão do processo de conhecimento dentro da organização, "a Gestão de Pessoas assume diversas funções dentro das organizações, dentre elas, o planejamento da força de trabalho ocupa papel essencial, estando intimamente relacionado ao cumprimento dos 
objetivos estratégicos da empresa" (Tocantins, 2018, p. 17).

Dessa forma afirma-se a significação da gestão do conhecimento para a instituição e na próxima seção apresenta-se uma análise sobre as legislações que norteiam o processo de desenvolvimento de pessoas.

\subsection{Desenvolvimento de pessoas: Legislações nacionais}

Os servidores da instituição são geridos pela Lei n. 8.112/1990, que instituiu o Regime Jurídico dos Servidores Públicos da União, das autarquias, entre outros, regulamentou as atribuições e as responsabilidades do servidor público, na estrutura organizacional. Essa Lei rege a vida funcional dos servidores, traz direitos, deveres, entre outros (Lei n. 8.112, 1990).

Em 1996 foi aprovada a Lei n. 9.394 (Lei n. 9.394, 1996), que estabelece as Diretrizes e Bases da Educação Nacional, apresentando em seu Art. 62 o processo de formação continuada dos profissionais da educação, liberou-se a utilização de diversos recursos e tecnologias de educação a distância no desenvolvimento dos profissionais da educação, e em seu Art. 62-A determina a obrigatoriedade das Instituições de todas as instâncias estatais de promover a formação continuada dos seus profissionais. Assim, existe a obrigatoriedade das instituições de ensino em promover a formação continuada dos seus profissionais visando uma educação de qualidade.

A legislação apresentada assegura o direito à formação do servidor e garante, através de critérios legais, o afastamento das atividades laborais para o desenvolvimento de formação, até o período de agosto de 2019.

Em 2019 o Presidente da República, Sr. Jair Messias Bolsonaro, em 28 de agosto de 2019, publicou o Decreto n. 9.991/2019, em que reestruturou a organização das capacitações dentro das instituições federais, dispondo-se então da Política Nacional de Desenvolvimento de Pessoas (PNDP); com a criação de alguns instrumentos de controle na execução dessa política, instrumentos como o Plano de Desenvolvimento de Pessoas (PDP), que orienta a produção de um relatório anual de execução, desde suas ações de desenvolvimento até a justificativas de não realização de ações previstas.

O controle dessa política é gerido pelo órgão central do Sistema de Pessoal Civil da Administração Pública Federal (SIPEC). Pretende-se com o PDP alinhar as ações de desenvolvimento do órgão ou da entidade, estabelecendo metas, atendendo as necessidades administrativas e norteando ações de desenvolvimento, com planejamento e princípios da economicidade e eficiência, conforme estabelece o Decreto n. 9.991/2019, itens I a IV, do $\S 1^{\circ}$ do Art. $3^{\circ}$, transcrito a seguir:

Art. $3^{\circ}$ Cada órgão e entidade integrante do SIPEC elaborará anualmente o respectivo PDP, que vigorará no exercício seguinte, com a finalidade de elencar as ações de desenvolvimento necessárias à consecução de seus objetivos institucionais.

$\S 1^{\circ}$ O PDP deverá:

I - Alinhar as ações de desenvolvimento e a estratégia do órgão ou da entidade;

II - Estabelecer objetivos e metas institucionais como referência para o planejamento das ações de desenvolvimento;

III - Atender às necessidades administrativas operacionais, táticas e estratégicas, vigentes e futuras;

IV - Nortear o planejamento das ações de desenvolvimento de acordo com os princípios da economicidade e da eficiência (Decreto n. 9.991, 2019).

O Decreto n. 9.991 de 2019, além de nortear as ações de desenvolvimento de pessoas, regulamentou a quantidade de servidores que terão direito a esse processo de formação, como também o período e os critérios para essa formação, reduzindo, dessa forma, os percentuais de pessoas que conseguem se afastar durante um determinado período.

Segundo as orientações do Decreto n. 9.991/2019, cada órgão ou instituição precisa mostrar transparência de suas ações de desenvolvimento, iniciando pela ampla divulgação da construção do Plano de Desenvolvimento de Pessoas, com a realização do levantamento das necessidades de desenvolvimento de seus servidores. Depois de confeccionado o PDP é encaminhado à autoridade máxima da instituição/órgão para aprovação, após sua aprovação, o PDP é encaminhado ao SIPEC, 
local em que é analisado, verificando-se as formações que poderão ser atendidas pelas escolas de governo, posteriormente é devolvido aos órgãos de origem para a execução das ações não transversais, que não foram atendidas pelas escolas de governo.

O Decreto n. 9.991 de 2019 apresentou a necessidade de divulgação de todos os gastos feitos com o plano de desenvolvimento de pessoas, seja com pessoal, com diárias e passagens, com pagamento de substituições de cargos de gestão ou com encargos referentes às inscrições de cursos.

No final do ano de 2019, publicou-se a Instrução Normativa n. 201, de 11 de setembro de 2019, que esclareceu quais foram os procedimentos e os critérios para a implementação do PDP nas instituições federais, estabeleceu prazos e condições para atender os procedimentos e as orientações para a implantação da Política Nacional de Desenvolvimento de Pessoas (PNDP) (Decreto n. 9.991, 2019).

A Instrução Normativa n. 201/2019 definiu o conceito de ação de desenvolvimento ou capacitação, esclareceu que as competências transversais foram comuns aos servidores de órgãos ou entidades do SIPEC, reforçou a ampla divulgação do PDP e faz outros apontamentos como os prazos da execução do planejamento do PDP e, também, a disseminação do conhecimento obtido nas ações de desenvolvimento, a responsabilização e atribuições da Chefia e dos procedimentos administrativos para requerer uma ação de desenvolvimento.

Em fevereiro de 2021, tentando simplificar o quantitativo de instruções relacionadas ao processo de desenvolvimento de pessoas, a Secretaria de Gestão e Desempenho de Pessoal/MEC divulgou a Instrução Normativa n. 21, de 2021, em que revogou a Instrução Normativa n. 201, de 11 de setembro de 2019; a Instrução Normativa n. 78, de 12 de agosto de 2020; a Instrução Normativa n. 19, de 28 de janeiro de 2021; a Portaria Conjunta n. 102, de 09 de outubro de 2019; a Portaria Conjunta n. 56, de 04 de setembro de 2020; a Portaria n. 101, de 8 de outubro de 2019; e a Portaria n. 16, de 13 de maio de 2020 (Instrução Normativa n. 21, 2021).

Com essa nova IN n. 21, de 2021, o governo regulamentou o período das revisões dos Planos de Desenvolvimento de Pessoas, passando a ser revisado trimestralmente, especificou-se o que é a necessidade de desenvolvimento, sendo a identificação do desempenho esperado pelo servidor e o desempenho atual, sendo assim a lacuna a ser complementada pela capacitação, para que o servidor chegue ao resultado esperado (Instrução Normativa n. 21, 2021).

A IN n. 21/2021 afirma que a ação de desenvolvimento de pessoas é uma atividade de aprendizagem que impulsiona o desempenho esperado referente às atribuições públicas. Essa Instrução Normativa também conceitua as competências transversais, afirmando que são as ações de desenvolvimento que contribuem para o trabalho em diferentes contextos organizacionais, também foram conceituadas as competências de liderança; as modalidades de ensino, que poderão ser presencial, EAD ou híbrida; a necessidade de supervisão em cursos de capacitação para Licença Capacitação; acompanhamento hierárquico da chefia do servidor, que deve fazer a aprovação do relatório das ações de formação desenvolvida (Instrução Normativa n. 21, 2021).

De acordo com a Instrução Normativa n. 21 de fevereiro de 2021, compete aos servidores, com o apoio da chefia imediata, participar das ações as quais se inscreveram, compartilhar os conhecimentos obtidos, utilizar os conhecimentos obtidos na realização do seu trabalho e fornecer as informações que permitam a avaliação da ação de desenvolvimento. À chefia do servidor, compete estimular a participação dos servidores em ações de desenvolvimento realizadas pelo órgão, acompanhar a eficácia e a efetividade da ação, apoiar o servidor na disseminação do conhecimento (Instrução Normativa n. 21, 2021).

No Quadro 1 apresenta-se um resumo das principais legislações que regulamentam a carreira do servidor público. 
Quadro 1 - Políticas nacionais voltadas para desenvolvimento de pessoas.

\begin{tabular}{|c|c|}
\hline $\begin{array}{l}\text { Lei n. } 9.394 / 1996 \\
\text { Lei de Diretrizes e } \\
\text { Bases da Educação } \\
\text { Nacional }\end{array}$ & $\begin{array}{l}\text { Estabelece as Diretrizes e Bases da Educação Nacional, aplicando a obrigatoriedade da formação continuada } \\
\text { dos profissionais da educação. } \\
\text { Para esse processo a legislação apresentou que poderão ser usados recursos tecnológicos para o } \\
\text { desenvolvimento das formações. }\end{array}$ \\
\hline & $\begin{array}{l}\text { Cria-se a Política Nacional de Desenvolvimento de Pessoas (PNDP), legislando sobre os critérios para o } \\
\text { controle das ações voltadas para o desenvolvimento de pessoas. } \\
\text { Esta Lei obriga todas as instituições federais a produzir um plano de desenvolvimento de pessoas, esse plano é } \\
\text { anual e deve ser encaminhado ao SIPEC, para análise das necessidades de desenvolvimento. } \\
\text { Devolvendo às instituições apenas as ações não atendidas pelas escolas de governo. } \\
\text { Centralizando assim as demandas transversais de necessidades de desenvolvimento. } \\
\text { Regulamentou o quantitativo de servidores que consegue afastar-se para a capacitação e também obriga a } \\
\text { divulgação dos gastos com estas ações. }\end{array}$ \\
\hline $\begin{array}{l}\text { ção Normativa } \\
1 / 2019 \\
\text { cretaria de } \\
\text { o e } \\
\text { mpenho de } \\
\text { al/MEC }\end{array}$ & $\begin{array}{l}\text { Essa normativa veio para esclarecer o Decreto n. } 9.991 / 2019 \text {, sobre o que são competências transversais; } \\
\text { Reforçou a obrigatoriedade de acompanhamento da chefia sobre a ação de capacitação, e sobre a necessidade } \\
\text { da disseminação do conhecimento por parte da pessoa capacitada. } \\
\text { Ela também conceitua as ações de desenvolvimento. }\end{array}$ \\
\hline $\begin{array}{l}\text { Instrução Normativa } \\
\text { n. } 21 / 2021 \\
\text { da Secretaria de } \\
\text { Gestão e } \\
\text { Desempenho de } \\
\text { Pessoal/MEC }\end{array}$ & $\begin{array}{l}\text { Revogou diversas legislações que regulamentavam a capacitação, publicadas no ano de } 2019 \text { e 2020, como: a } \\
\text { IN n. 201/2019, a IN n. 78/2020; IN n. 19/2021, a Portaria n. 102/2019 entre outras. } \\
\text { Regulamentou as revisões do PDP, sendo realizadas trimestralmente; } \\
\text { Especifica o que é ação de desenvolvimento; } \\
\text { Estabelece o período que o PDP deve ser elaborado, especifica as informações necessárias que devem conter } \\
\text { no PDP e nos processos de afastamentos dos servidores quanto a orientação referente as ações de } \\
\text { desenvolvimento dos servidores e compromisso de acompanhamento da chefia, e da instituição na orientação, } \\
\text { desenvolvimento e acompanhamento das ações de desenvolvimento de pessoas. A IN n. 01/2021 também } \\
\text { retrata a obrigatoriedade do servidor capacitado em cadastrar e manter atualizado seu currículo no Banco de } \\
\text { Talentos do Governo Federal. }\end{array}$ \\
\hline
\end{tabular}

Fonte: Autores.

Sendo o desenvolvimento de pessoas uma necessidade e uma obrigatoriedade, as instituições precisam organizar seu processo de desenvolvimento de pessoas, seguindo-se sob as orientações nacionais, desenvolvendo ações que corroborem com esse processo.

\subsection{Descrição do processo de desenvolvimento de pessoas dentro do IFMT}

A formação continuada e/ou desenvolvimento de pessoas é uma necessidade para os servidores do IFMT, sendo critérios exigidos para a progressão funcional. Assim a pesquisa identificou a necessidade de formação para a carreira docente sendo a Lei n. 12.772 de dezembro de 2012, que dispõe sobre a estruturação do Plano de Carreiras e Cargos de Magistério Federal:

Art. 14. A partir da instituição do Plano de Carreiras e Cargos de Magistério Federal, o desenvolvimento na Carreira de Magistério do Ensino Básico, Técnico e Tecnológico ocorrerá mediante progressão funcional e promoção, na forma disposta nesta Lei.

$\S 1^{\circ}$ Para os fins do disposto no caput, progressão é a passagem do servidor para o nível de vencimento imediatamente superior dentro de uma mesma classe, e promoção, a passagem do servidor de uma classe para outra subsequente, na forma desta Lei.

$\S 2^{\circ}$ A progressão na Carreira de Magistério do Ensino Básico, Técnico e Tecnológico ocorrerá com base nos critérios gerais estabelecidos nesta Lei e observará, cumulativamente:

I - O cumprimento do interstício de 24 (vinte e quatro) meses de efetivo exercício em cada nível; e

II - Aprovação em avaliação de desempenho individual. (Grifo nosso) (Lei n. 12.772, 2012). 
Esse desempenho esperado do servidor envolve sua formação continuada, pesquisas, projetos, atividades laborais, evidenciando assim a necessidade de atualização profissional (Lei n. 12.772, 2012).

As regras de desenvolvimento também servem para os servidores Técnicos Administrativos, conforme estabelece a Resolução n. ${ }^{\circ} 031$ de setembro de 2011 (Resolução n. ${ }^{\circ}$ 31, 2011), que dispõe sobre o Programa de Avaliação de Desempenho dos Servidores Técnico Administrativos em Educação do Instituto Federal de Educação, Ciência e Tecnologia de Mato, como evidencia-se a seguir:

Art. $5^{\circ}$. O Programa de Avaliação de Desempenho tem por objetivos específicos:

I - Estimular o trabalho coletivo, visando à ampliação do nível de participação dos servidores no planejamento institucional;

II - Fornecer informações que permitam um planejamento estratégico, visando o desenvolvimento de pessoal e da instituição;

III - propiciar condições adequadas à melhoria dos processos de trabalho;

IV - Identificar os aspectos facilitadores e dificultadores ao desempenho, relacionados às condições de trabalho coletivo e individual;

V - Subsidiar a elaboração de programa de capacitação, de dimensionamento das necessidades institucionais, de pessoal e de política de saúde ocupacional;

VI - Aferir o mérito para progressão. (Resolução n. ${ }^{\circ}$ 31, 2011).

De acordo com as legislações que regem a carreira do cargo docente (Lei n. 12.772, 2012) e do cargo Técnico Administrativo (Resolução n. ${ }^{\circ}$ 31, 2011), percebe-se que a progressão na carreira do servidor está diretamente ligada aos processos que envolvem sua formação e/ou desenvolvimento, afirmando assim a necessidade de compreensão do processo organizativo do desenvolvimento de pessoas.

O IFMT é uma instituição de ensino atuando com servidores docentes e técnicos administrativos, necessitando desse aperfeiçoamento contínuo para os servidores que levam a Educação Profissional e Tecnológica (EPT) a sociedade, sendo essa uma modalidade de educação que está em constante transformação, sendo dever das instituições promover a formação de seus colaboradores, atualizando-os quantos as alterações da modernidade.

Assim o IFMT proporciona ao servidor a continuação da formação, através de programas de pós-graduação, de desenvolvimento de cursos de curta e longa duração, palestras, oficinas, Workshop e também autoriza o afastamento das atividades laborais para que os servidores desenvolvam ações de capacitação.

Tudo isso visando a qualidade do serviço prestado à sociedade, assim o servidor se desenvolve profissionalmente, $\mathrm{e}$ desempenha com eficiência, suas atividades laborais. Seguindo-se a visão do IFMT, formando o cidadão para a vida e para o mundo do trabalho, compreendendo o processo de ensino aprendizagem desde as concepções pedagógicas até a prática do dia a dia.

A continuidade da formação possibilitará ao servidor a preparação necessária para enfrentar os desafios da constante transformação do mundo do trabalho conforme nos afirma (Brasil, 2004).

Decreto n. 2.208, art. $3^{\circ}$, I, que instituiu a oferta de cursos modulares, segmentados, com grande variação de carga horária, legitimando "... a qualificação e reprofissionalização de trabalhadores, independentemente de escolaridade prévia...", bem como o aproveitamento de outras experiências profissionais dos trabalhadores que poderiam ser “... objeto de avaliação, reconhecimento e certificação para prosseguimento ou conclusão de estudos" (Portaria n. 646/97, que regulamentou o art. 39 a 42 da LDB) IN". (Brasil, 2004, p. 12)

Para alcançar esses objetivos o IFMT possui algumas regras e regulamentos como: O Plano de Desenvolvimento Institucional (PDI), A Política de capacitação dos servidores Resolução 047 de 2019, e também possui o Plano de Desenvolvimento de Pessoas (PDP) iniciado no ano de 2020, que veio substituir o antigo Plano Anual de Capacitação (PAC) que esteve vigente até meados do ano de 2019. 
O Plano de Desenvolvimento Institucional (PDI) do IFMT é um planejamento para duração de três anos (trienal), com ações e estratégias criadas pela Reitoria e demais campi da Instituição (IFMT, 2019), para a orientação, acompanhamento e monitoramento dos objetivos institucionais, entre essas ações estão as atividades desenvolvidas pela área de gestão de pessoas.

O PDI, 2019-2023 conceitua o trabalho como princípio educativo, sendo que "o fazer educativo no contexto da educação profissional não pode estar desconectada de elementos como a ciência, a cultura, o trabalho, que, integrados, podem orienta-se pelas diretrizes para uma educação que vise à autonomia dos sujeitos" (IFMT, 2019, p. 80).

Além disso, consta no PDI 2019-2023 que a Diretoria Sistêmica de Gestão de Pessoas (DSGP), com o apoio das Coordenações de Gestão de Pessoas dos campi, é responsável pelo desenvolvimento das formações continuadas, acompanhando os 1.900 servidores das carreiras de Docente e Técnicos Administrativos, criando as ações que levam ao desenvolvimento do servidor. Para isso, a Instituição estabeleceu a política de capacitação dentro do IFMT, que teve como objetivo preparar os servidores para o desempenho de suas atribuições, pensando na qualidade do serviço público.

A política de capacitação segue como princípio geral a educação continuada, tendo por objetivo preparar os servidores para o desempenho das suas atividades no IFMT, além de estimular a geração, absorção e transmissão/mediação de novos conhecimentos individuais e corporativos (IFMT, 2019, p. 81).

O PDI (2019-2023) teve como base o Decreto n. 5.707 de 2006, que foi revogado e substituído pelo Decreto n. 9.991, de 28 de agosto de 2019, o programa de formação continuada teve sua finalidade na qualidade do serviço público, na valorização do servidor e, no desenvolvimento de competências, seguindo-se o objetivo da Instituição. Estas formações justificam o crescimento institucional que hoje possui, além da Reitoria, 19 unidades, sendo 14 Campi e 5 Campi Avançados, com grande número de novos servidores, que lidam diretamente com os recursos técnicos e/ou pedagógicos (IFMT, 2019).

Para alcançar seus objetivos ligados à gestão de pessoas, a Instituição, por meio do seu PDI (IFMT, 2019, p. 29), traça alguns objetivos estratégicos como "Objetivo n. 02 - Promover a qualidade de vida dos servidores no trabalho, nas relações Interpessoais e nas ações institucionais".

A seguir são apresentados o Quadro 2 e o Quadro 3 que se referem à explanação quanto aos objetivos institucionais em relação ao desenvolvimento do servidor, detalhando a estratégia organizacional, apresentando indicadores, prazos, metodologia de controle e também o setor responsável pela avaliação do resultado e planejamento. 
Quadro 2 - Indicador de desempenho segundo o PDI: Promover a qualidade de vida dos servidores, aumentando o percentual de capacitados.

\begin{tabular}{|l|l|}
\hline Objetivo estratégico n. 2 & $\begin{array}{l}\text { Promover a qualidade de vida dos servidores no trabalho, nas relações interpessoais e nas } \\
\text { ações institucionais }\end{array}$ \\
\hline Detalhamento & Descrição \\
\hline Indicador 1 & Percentual de servidores capacitados em educação regular \\
\hline Polaridade & Quanto maior melhor \\
\hline Periodicidade & Anual \\
\hline Prazo máximo de mensuração & Fevereiro \\
\hline Responsabilidade pela apuração & PROPES \\
\hline Fonte de dados & Sistema SUAP ou planilhas de controle \\
\hline Metodologia da coleta de dados & Análise e extração de dados no sistema e/ou planilhas \\
\hline Fórmula de cálculo & SerCap = (Número de servidores capacitados) / (Número total de servidores) X 100 \\
\hline Meta & $10 \%$ \\
\hline
\end{tabular}

Fonte: Plano de Desenvolvimento Institucional - PDI 2019-2023 (IFMT, 2019, p. 31).

O Quadro 3 evidencia o objetivo estratégico, com indicador de n. 2, em que orienta a ampliação do número de servidores em cursos de curta duração.

Quadro 3 - Indicador de desempenho segundo o PDI: Aumentar a participação em capacitações.

\begin{tabular}{|l|l|}
\hline Objetivo estratégico n. 2 & $\begin{array}{l}\text { Promover a qualidade de vida dos servidores no trabalho, nas relações interpessoais e nas } \\
\text { ações institucionais }\end{array}$ \\
\hline Detalhamento & Descrição \\
\hline Indicador 2 & Número de servidores capacitados em cursos/eventos de curta duração \\
\hline Polaridade & Quanto maior, melhor. \\
\hline Periodicidade & Anual \\
\hline Prazo máximo de mensuração & Fevereiro \\
\hline Responsabilidade pela apuração & DSGP \\
\hline Fonte de dados & Plano anual de capacitação e a pasta funcional \\
\hline Metodologia da coleta de dados & Análise e extração de dados dos documentos \\
\hline Fórmula de cálculo & SerCap = (Número de servidores capacitados) / (Número total de servidores) X 100 \\
\hline Meta & $30 \%$ \\
\hline
\end{tabular}

Fonte: Plano de Desenvolvimento Institucional - PDI 2019-2023 (IFMT, 2019, p. 31). 
O PDI apresenta os objetivos institucionais direcionados ao desenvolvimento dos servidores do IFMT, orientando o desenvolvimento de ações que colaborem no processo de trabalho e também para as relações de trabalho, evidenciando a necessidade de aumentar o número de participações em cursos de capacitação.

Os recursos envolvidos no processo de desenvolvimento de pessoas fazem parte do orçamento do IFMT, e compete à Diretoria Sistêmica de Gestão de Pessoas supervisionar a execução do plano de capacitação e decidir sobre os casos não previstos (IFMT, 2019).

Com o incentivo à qualificação, o IFMT pretende preparar os servidores para suas atividades laborais, fortalecendo a pesquisa, as práticas investigativas, a produção científica, entre outros. Também visa desenvolver os servidores, proporcionando condições de aprendizados aos técnicos administrativos, com apoio financeiro, afastamento com remuneração, cursos de pós-graduação e diversos cursos de curta duração.

Até o início do ano de 2019, as ações de capacitação no IFMT foram realizadas de acordo com o Plano Anual de Capacitação (PAC) do IFMT (IFMT, 2018), existia uma previsão orçamentária para a formação continuada, e esse processo era realizado da seguinte forma: cada campus e a Reitoria tinha um valor previsto para os gastos com capacitação, o valor geral era previsto pelo Ministério da Economia, a Reitoria fazia a divisão entre Reitoria, Campi e Campi avançados, cada um tinha autonomia para planejar e promover suas capacitações e/ou formação (IFMT, 2018).

Os cursos oferecidos pela Reitoria tinham a intenção de desenvolver e aperfeiçoar os conhecimentos dos servidores com a finalidade de aprimorar a qualidade dos serviços públicos. Assim, o planejamento de cursos visava não só o desenvolvimento do servidor, mas, também o desenvolvimento da Instituição, com cursos que alinhavam o desenvolvimento do servidor e as metas da Instituição e das demandas sociais (IFMT, 2018).

O Plano Anual de Capacitação (PAC) do IFMT era desenvolvido em parceria com todos os campi, que foram consultados na hora do planejamento das ações de capacitação para que de forma conjunta planejasse a oferta de cursos que atendam às necessidades de desenvolvimento da maioria, possibilitando, ainda, fazer contratações para cursos in company visando um menor custo-benefício.

O Plano Anual de Capacitação do IFMT 2019 com base em levantamento de necessidades realizado junto às PróReitorias e Diretorias Sistêmicas da Reitoria, para conhecer as demandas de capacitação para as diferentes áreas, considerando que as demandas em comum dos campi são encaminhadas às Pró-Reitorias e Diretorias Sistêmicas (IFMT, 2018, p. 01).

Depois da finalização do planejamento do PAC, o Departamento de Desenvolvimento de Pessoas do IFMT fazia o planejamento da execução das formações, desenvolvendo projetos para os cursos solicitados, coordenando sua organização, até a fase final de certificação. Os cursos foram oferecidos aos servidores do IFMT, entretanto, dependendo da necessidade de outros órgãos, também poderiam ser feitas reservas de vagas, como o Tribunal Regional do Trabalho (TRT), a Universidade Federal de Mato Grosso (UFMT) e o Instituto Brasileiro do Meio Ambiente e dos Recursos Naturais Renováveis (IBAMA).

As formações desenvolvidas pelo IFMT tinham uma ampla divulgação através do site do IFMT, dos e-mails institucionais dos servidores e das chefias de departamentos. As prioridades para as inscrições seriam daqueles servidores que desenvolvem atividades laborais de acordo com o curso desenvolvido.

As formações continuadas de pós-graduação foram desenvolvidas por edital específico, com diversos critérios de seleção, sendo os principais o servidor já estar aprovado em curso de pós-graduação, o tempo de serviço e a área de atuação do servidor.

Segundo o Plano Anual de Capacitação (IFMT, 2018), os cursos pleiteados pelos servidores deveriam estar alinhados às suas formações, às necessidades de desenvolvimento institucional e do trabalho realizado pelo servidor. 
Além disso, a preocupação com a capacitação no IFMT justifica-se pelo contexto de crescimento institucional, com o ingresso de novos servidores, demandando que nossas bases sejam estruturadas. Neste contexto, enfrentamos tem desafio quantitativo e qualitativo em termos de capacitação. O quantitativo consiste em criar condições para que os programas de capacitação sejam efetivos e acessíveis a todos os servidores. O qualitativo refere-se à infraestrutura e técnico pedagógicos condizentes com a demanda (IFMT, 2018, p. 01).

De acordo com IFMT (2018), a instituição possuía um valor orçamentário para capacitação que é previsto para ser gasto no ano civil, dessa forma as capacitações solicitadas pelos seus gestores e servidores precisam de consonância com esse valor orçamentário e com o PDI. Assim, a Reitoria em conjunto com os demais Campi propunha um plano anual de capacitação, que abrange as formações gerais, para executá-lo, lança-se editais de afastamento para capacitação formal e também cada campus tem autonomia para promover outros cursos que visam atender à demanda de formação específica.

No ano de 2019 o IFMT publicou a Resolução n. ${ }^{\circ} 047$ de 2019 instituindo a Política de Desenvolvimento e Capacitação de Pessoas do IFMT, sendo criada baseada na Lei n. 8.112/1990, na LDB de 1996 (Lei n. 9394, 1996), dentre outros decretos ela também teve base na nova legislação que tratou sobre a capacitação, o Decreto n. 9.991 de agosto de 2019 (Resolução n. ${ }^{\circ}$ 047, 2019).

Este Regulamento trata da Política de Desenvolvimento e Capacitação de Pessoas do Instituto Federal de Educação, Ciência e Tecnologia de Mato Grosso - IFMT e encontra-se consubstanciado nos termos da Lei n. 8.112, de 11/12/1990; da Lei n. 9.394, de 20/12/1996; da Lei n. 9.527, de 10/12/1997; da Lei n. 11.907, de 02/02/2009; do Decreto n. 7.312, de 22/12/2010; do Decreto n. 5.824, de 29/06/2006; da Lei n. 11.091, de 12/01/2005; da Lei n. 12.772, de 28/12/2012; do Decreto n. 9.991, de 28/08/2019, e demais normas vigentes. (Resolução n. ${ }^{\circ} 047,2019$, p. $01)$.

O objetivo da Resolução n. ${ }^{\circ}$ 047/2019 é regulamentar a política de desenvolvimento e capacitação de pessoas, proporcionando uma segurança institucional nos procedimentos administrativos com um processo transparente, possibilitando a ampliação do desempenho e uma eficiência dos serviços educacionais, promovendo o desenvolvimento de servidores e regulamentando os treinamentos dentro do IFMT.

As formações continuadas ou processos de capacitação dentro do IFMT acontecem de modo presencial ou a distância podendo ser: formação acadêmica - graduação e pós-graduação; treinamentos externos e internos; participação em congressos; participação em seminários, treinamentos instituídos, capacitação de curta e longa duração, entre outras (Resolução 047, 2019).

A política produzida pela Resolução n. ${ }^{\circ} 047 / 2019$ (Resolução n. ${ }^{\circ}$ 047, 2019) procura zelar pela transparência nas ações de desenvolvimento dentro da Instituição, regulamentou o levantamento de demanda, o cronograma deste e as atribuições das chefias nesse processo. Depois de levantada a demanda de desenvolvimento é elaborado o PDP (Planejamento de Desenvolvimento de Pessoas), que precisa da aprovação do Reitor e enviado ao Sistema de Pessoal Civil da Administração Federal (SIPEC) para verificação das demandas que poderão ser atendidas pelas escolas de governo, as não atendidas voltam à Instituição para execução das ações.

O Art. $4^{\circ}$ do regulamento que tratou da Política de Desenvolvimento e Capacitação de Pessoas do IFMT abrange toda e qualquer ação de desenvolvimento de pessoas, conforme citação:

Art. $4^{\circ}$ As ações de desenvolvimento e capacitação em programa de treinamento regularmente instituído para servidores no âmbito do IFMT serão desenvolvidas nos seguintes níveis:

I - Eventos de capacitação: cursos, oficinas, palestras, seminários, fóruns, congressos, simpósios, semana, jornada, invenção, colóquio, encontro e outras modalidades similares de eventos;

II - Educação formal: ensino fundamental, médio, profissionalizante, superior, aperfeiçoamento, especialização, mestrado, doutorado e pós-doutorado;

III - aprendizagem prática: compreendendo aprendizagem de serviço, intercâmbio, estudo em grupo nos termos do artigo 25 do Decreto n. 9.991/2019. (Resolução n. ${ }^{\circ}$ 047, 2019, p. 03). 
Todas as formações que acontecem durante o período de trabalho serão vistas com base na Resolução n. ${ }^{\circ}$ 047/2019, assuntos sobre horário especial de estudante, programas de pós-graduação, cursos de curta e longa duração, treinamentos, como também as condições para usufruir de qualquer tipo de formação ou afastamento para capacitação. Essa resolução também tratou dos processos para conseguir a formação, os critérios e os procedimentos administrativos para cada modalidade de afastamento.

No ano de 2020, o IFMT lançou o Plano de Desenvolvimento de Pessoas (PDP), em que se apresenta a descrição das necessidades de desenvolvimento levantadas pelos 19 campi, norteando o planejamento anual de ações que visem o desenvolvimento do servidor. Mantendo a orientação de que os objetivos de aprendizagem devem ser alinhados aos objetivos institucionais (IFMT, 2020).

O PDP foi desenvolvido sob as orientações do SIPEC quanto ao levantamento da necessidade de desenvolvimento. O Quadro 4 apresenta as orientações do Ministério da Economia para a construção do Plano de Desenvolvimento de Pessoas (PDP), sendo um guia de estruturação de como identificar a necessidade de desenvolvimento, para ao final prestar contas ao SIPEC (Brasil, 2020).

Quadro 4 - Estrutura geral da descrição de necessidade de desenvolvimento.

\begin{tabular}{|c|c|c|c|c|}
\hline INFORMAÇÕES & \multicolumn{2}{|c|}{ 1) O que as pessoas necessitam? } & 2) Do que são capazes se for & 3) Que resultado isso trará para \\
\hline $\begin{array}{c}\text { TIPO DE } \\
\text { INFORMAÇÃO }\end{array}$ & $\begin{array}{c}\text { Esforço de } \\
\text { Aprendizagem }\end{array}$ & $\begin{array}{c}\text { Objeto de } \\
\text { Aprendizagem }\end{array}$ & Capacidade Humana & Resultado Organizacional \\
\hline $\begin{array}{l}\text { COMO PODEM } \\
\text { SER } \\
\text { INDICADAS }\end{array}$ & $\begin{array}{lr}\text { Um verbo } & \text { que } \\
\text { indique o } & \text { esforço } \\
\text { necessário } & \text { para } \\
\text { aprender } & \text { sobre } \\
\text { determinado } & \\
\text { conteúdo. } & \end{array}$ & $\begin{array}{l}\text { Um tema geral (com } \\
\text { indicação de recorte de } \\
\text { interesse) que será } \\
\text { aprendido. }\end{array}$ & $\begin{array}{l}\text { De livre indicação de acordo } \\
\text { com a maturidade da } \\
\text { organização e o interesse } \\
\text { específico na capacidade a } \\
\text { desenvolver; pode ser usada } \\
\text { indicação de competência; de } \\
\text { comportamentos esperados para } \\
\text { a função/cargo; resultados ao } \\
\text { nível da pessoa. }\end{array}$ & $\begin{array}{l}\text { De livre indicação de acordo } \\
\text { com a maturidade da } \\
\text { organização em ter listados e } \\
\text { claros quais resultados } \\
\text { perseguem; podem ser usados } \\
\text { resultados estipulados e } \\
\text { presentes em planejamentos, } \\
\text { metas e objetivos institucionais } \\
\text { em qualquer nível. }\end{array}$ \\
\hline $\begin{array}{l}\text { EXEMPLO DE } \\
\text { NECESSIDADE }\end{array}$ & Aplicar & $\begin{array}{l}\text { Normas de } \\
\text { desenvolvimento } \\
\text { sustentável em } \\
\text { contratos } \\
\text { administrativos e ações } \\
\text { rotineiras do órgão. }\end{array}$ & $\begin{array}{l}\text { PARA gerir contratos que } \\
\text { atendam aos requisitos da A3P } \\
\text { e usar materiais e recursos de } \\
\text { modo racional. }\end{array}$ & $\begin{array}{l}\text { ALCANÇANDO a redução de } \\
35 \% \text { do consumo de papel; } \\
\text { redução dos custos com } \\
\text { cartuchos em 20\%; ampliação } \\
\text { de um ano da vida útil dos } \\
\text { aparelhos eletrônicos } \\
\text { comprados a partir de } 2019 \text {. }\end{array}$ \\
\hline
\end{tabular}

Fonte: Brasil (2020, p. 28).

O PDP é construído através do levantamento das demandas de formação de todos os servidores, em posterior, é feita uma análise pela autoridade máxima do órgão e depois é encaminhado ao SIPEC, que analisa as demandas transversais que poderão ser atendidas pelas escolas de governo e, por fim, é feita a devolutiva ao órgão de origem para a execução das ações, atendendo ao Decreto n. 9.991 de 2019.

Apresenta-se o Quadro 5 com uma breve explanação das regulamentações internas do IFMT, contendo informações sobre os processos que envolvem a formação continuada ou o desenvolvimento de pessoas. 
Quadro 5 - Regulamentações internas do IFMT voltadas para o desenvolvimento de pessoas.

\begin{tabular}{|c|c|}
\hline $\begin{array}{l}\text { PDI 2019-2023 } \\
\text { (IFMT, 2019) }\end{array}$ & $\begin{array}{l}\text { É uma regulamentação interna, em que orienta a comunidade do IFMT sobre a missão, visão, } \\
\text { estratégias, objetivos e metas institucionais do IFMT. } \\
\text { Fortalecendo a temática de formação, o PDI definiu o trabalho como princípio educativo, sendo } \\
\text { que os profissionais precisam estar conectados com a ciência, a cultura, o trabalho, para formar } \\
\text { cidadãos autônomos. } \\
\text { Consta nesse documento que a DSGP junto às coordenações dos demais campi foram } \\
\text { responsáveis pelo desenvolvimento de orientações, acompanhamento e desenvolvimento de ações } \\
\text { que visem a formação continuada do servidor. } \\
\text { Preparando os servidores para o desenvolvimento de suas atividades e estimulando a } \\
\text { transmissão/mediação de novos conhecimentos. } \\
\text { O PDI 2019-2023 foi baseado no Decreto n. 5.707/2006, revogado pelo Decreto n. 9.991/2019. }\end{array}$ \\
\hline $\begin{array}{l}\text { Plano Anual de Capacitação } \\
\text { (PAC) } \\
\text { (IFMT, 2018) }\end{array}$ & $\begin{array}{l}\text { Os PACs foram desenvolvidos até o ano de } 2019 \text {, sendo um regulamento interno do IFMT, com } \\
\text { planejamento de ações que levam ao desenvolvimento do servidor, alinhado com os objetivos } \\
\text { institucionais. Para desenvolvimento do PAC é realizado um levantamento de demanda para } \\
\text { capacitação, essa parte é construída pelas Pró-reitorias e Diretorias do IFMT, por fim é feita uma } \\
\text { análise pela DSGP, em que o PDP é finalizado e encaminhado para aprovação do Reitor. } \\
\text { Os PACs traziam o planejamento anual de cursos e também orientavam quem tinha o direito à } \\
\text { certificação, quais cursos foram oferecidos, e as regras/orientações sobre a desistência de } \\
\text { participantes. }\end{array}$ \\
\hline $\begin{array}{l}\text { Resolução IFMT n. 047/2019 } \\
\text { (Resolução n. 047, 2019) }\end{array}$ & $\begin{array}{l}\text { Institui a Política de Desenvolvimento e Capacitação de Pessoas do IFMT; } \\
\text { Substitui e revogou o Regulamento da Política de Capacitação do IFMT, a RPC n. 49/2018, que } \\
\text { tratava da política de capacitação dos servidores do Instituto Federal de Educação, Ciência e } \\
\text { Tecnologia de Mato Grosso (IFMT). } \\
\text { A Resolução n. 047/2019 regulamentou a política de desenvolvimento e a capacitação de pessoas, } \\
\text { proporcionando uma segurança institucional nos procedimentos administrativos, aprimorando a } \\
\text { transparência e a satisfação do servidor e ampliando a eficiência dos serviços educacionais. } \\
\text { Definiu o que é uma ação de desenvolvimento de pessoas, sendo cursos de curta e longa duração, } \\
\text { educação formal, prática ou treinamento em serviço. } \\
\text { Estabelece as orientações e os procedimentos necessários para solicitar ou participar de } \\
\text { determinada ação de desenvolvimento. }\end{array}$ \\
\hline $\begin{array}{l}\text { Plano de Desenvolvimento de } \\
\text { Pessoas PDP } \\
\text { (IFMT, 2020) }\end{array}$ & $\begin{array}{l}\text { O PDP é um planejamento anual de ações de desenvolvimento. } \\
\text { Realizado através do levantamento das demandas de todos os servidores. Em posterior, é feita } \\
\text { uma análise para SIPEC e, por fim, é devolvido às necessidades de desenvolvimento não } \\
\text { contempladas pelas escolas de governo, de acordo com o Decreto n. } 9.991 / 2019 \text {. }\end{array}$ \\
\hline
\end{tabular}

Fonte: Autores.

Evidenciou-se o processo de desenvolvimento de pessoas dos servidores do IFMT, analisando suas legislações, regulamentos, normativas e orientações quanto à organização da instituição e quanto à formação continuada e/ou desenvolvimento dos servidores.

$\mathrm{O}$ artigo abordou as legislações e normativas nacionais e as regulamentações internas que norteiam o processo de desenvolvimento de pessoas dentro do IFMT. Este artigo foi desenvolvido através de um recorte do projeto de Mestrado em Educação Profissional e Tecnológica em Rede Nacional (ProfEPT) intitulado de Gestão da Formação Continuada - IFMT: Plataforma de Talentos.

Foi identificado um rico processo de formação continuada dos servidores do IFMT, podendo-se inferir que dentro da instituição há um significativo número de servidores qualificados e aptos a compartilhar o conhecimento. Sendo assim, o artigo traz como sugestão que a Instituição construa e/ou aprimore seu processo de gestão do conhecimento, iniciando com a construção de um repositório com uma base de dados de servidores aptos a desenvolverem ações de capacitação, isso corrobora com a valorização do seu capital intelectual, os dados desse repositório subsidiarão ações de desenvolvimento, abrindo espaço para a disseminação ou o compartilhamento de saberes, como cursos, palestras, oficinas, entre outros.

Por fim, foi atendido o objetivo da pesquisa em analisar as legislações e normativas que compõem o processo de desenvolvimento de pessoas dentro do IFMT, corroborando com o entendimento da comunidade interessada, em especial os 
servidores da instituição que precisam conhecer essa organização, a qual estão inseridas formas de capacitação que colaboraram com seu desempenho profissional e com serviço prestado a comunidade IFMT.

\section{Considerações Finais}

Através desta pesquisa foram analisadas as legislações e normas que perpassam o processo de desenvolvimento dos servidores do IFMT. Foram analisados o referencial teórico, que trabalha com a temática desenvolvimento de pessoas, Política Nacional de Desenvolvimento de Pessoas, O Plano de Desenvolvimento Institucional e as regulamentações internas do IFMT, que norteiam o processo de desenvolvimento dos servidores, corroborando com o entendimento da comunidade IFMT sobre a temática estudada.

Sendo o objeto de pesquisa uma instituição de ensino, local em que os servidores precisam de qualificação e atualização contínua, que contribua com os objetivos institucionais, a formação continuada e/ou desenvolvimento de pessoas são grandes aliadas dos educadores, contribuindo para suas práxis, colaborando para um ensino reflexivo e dando significado aos ambientes organizacionais envolvidos no processo de ensino-aprendizagem.

A gestão do conhecimento é uma ferramenta necessária para a qualidade do serviço público, que visa um ensino de qualidade que traga reflexão e contextualização, contribuindo com o processo de desenvolvimento de pessoas, promovendo o crescimento e o aprimoramento da sua prática pedagógica, possibilitando uma formação para além do trabalho, formando um ser social, preparado e capaz de intervir em seu meio, colaborando com a superação da desigualdade social.

Ao corroborar com o entendimento sobre o processo de desenvolvimento de pessoas dentro do IFMT, atendemos aos objetivos da pesquisa, em que foram explanadas as legislações, regulamentos e normas pertinentes a esse processo, contextualizando-as.

Como sugestão para continuação da pesquisa, propõe-se mapear os servidores que receberam capacitação para desenvolver e implantar um banco de talentos próprio, sendo um meio de sistematizar o capital intelectual, colaborando com a gestão do conhecimento dentro da instituição. O Banco de Talentos poderá subsidiar ações de capacitação, que corrobora com a formação e desenvolvimento dos servidores, visando a qualidade do serviço público que envolve diversas ações/fatores, como o plano de carreira, desenvolvimento profissional, estrutura física, segurança, investimento, entre outros.

\section{Referências}

Acquesta, J. C. (2018). O Que é Gestão do conhecimento? Conversa com Especialistas em GC no Brasil. Sociedade Brasileira de Gestão do Conhecimento (SBGC). E-Book (Organização: Mariana Lima, Layout e ilustrações: Avelar Fortunato). https://www.academia.edu/38 931078/Gest\%C3\%A3o_do_conhecimento.

Batista, F. F. et al. (2005). Gestão do conhecimento na administração pública. Instituto de Pesquisa Econômica Aplicada (Ipea). http://repositorio.ipea.gov.br/bitstream/11058/892/1/TD\%201095.pdf.

Brasil (2004). A formação de professores está presente nos pressupostos da "Proposta em Discussão: Políticas Públicas para a Educação Profissional e Tecnológica". http://portal.mec.gov.br/setec/arquivos/pdf/p_publicas.pdf.

Brasil (2020). Ministério da Economia. Política Nacional de Desenvolvimento de Pessoas. Guia para Elaboração do Plano de Desenvolvimento de Pessoas, p. 115. https://capacitar.ufba.br/sites/capacitar.ufba.br/files/guia_elaboracao_pdp2021_verso_final_com_anexos.pdf.

Decreto n. 9.991, de 28 de agosto de 2019. Dispõe sobre a Política Nacional de Desenvolvimento de Pessoas da administração pública federal direta, autárquica e fundacional, e regulamenta dispositivos da Lei n. 8.112, de 11 de dezembro de 1990, quanto a licenças e afastamentos para ações de desenvolvimento. 2019. Diário Oficial [da] República Federativa do Brasil, http://www.planalto.gov.br/ccivil_03/_Ato2019-2022/2019/Decreto/D9991.htm.

Gil, A. C. (2008). Métodos e técnicas de pesquisa social. Ed. Atlas S. A. (6a ed.), Atlas.

GIL, A. C. (2009). Estudo de Caso. Atlas.

Gonzalez, R. V. D., \& Martins, M. F. (2017). O Processo de Gestão do Conhecimento: uma pesquisa teórico-conceitual. Gestão \& Produção, $24,248-265$. http://dx.doi.org/10.1590/0104-530X0893-15. 
Gozzi, M. P. (2012). O processo de gestão do conhecimento em comunidades virtuales de aprendizagem. Perspectivas em Gestão \& Conhecimento, 2(2), 3-14. https://dialnet.unirioja.es/servlet/articulo?codigo $=4264300$.

Instituto Federal de Mato Grosso (2018). Plano Anual de Capacitação - IFMT 2019, do Instituto Federal de Mato Grosso. Cuiabá. 05 de dez. 2018. http://dsgp.ifmt.edu.br.

Instituto Federal de Mato Grosso (2019). Plano de Desenvolvimento Institucional - 2019-2023, do Instituto Federal de Mato Grosso http://prodin.ifmt.edu.br/media/filer_public/79/b8/79b8149b-821c-464d-afcf-b16bf21efd69/pdi_2019_v01.pdf.

Instituto Federal de Mato Grosso (2020). Plano de Desenvolvimento de Pessoas (PDP), do Instituto Federal de Mato Grosso. https://docs.google.com/spreadsheets/d/1-DcoFhP4S7Z0MjYngzVFdqrOXYb7xHwcTQmnrF3hhAw/edit\#gid=0.

Instrução Normativa n. 201, de 11 de setembro de 2019. Dispõe sobre os critérios e procedimentos específicos para a implementação da Política Nacional de Desenvolvimento de Pessoas, de que trata o Decreto n. 9.991, de 28 de agosto de 2019, pelos órgãos integrantes do Sistema de Pessoal Civil da Administração Federal - SIPEC. 2019. Diário Oficial [da] República Federativa do Brasil, http://www.in.gov.br/en/web/dou/-/instrucao-normativa-n-201-de-11-desetembro-de-2019-215812638.

Instrução Normativa n. 21, de $1^{\circ}$ de fevereiro de 2021. Ministério da Economia. Estabelece orientações aos órgãos do Sistema de Pessoal Civil da Administração Pública Federal - SIPEC, quanto aos prazos, condições, critérios e procedimentos para a implementação da Política Nacional de Desenvolvimento de Pessoas - PNDP de que trata o Decreto n. 9.991, de 28 de agosto de 2019. 2021. Diário Oficial [da] República Federativa do Brasil, https://www.in.gov.br/en/web/dou/-/instrucao-normativa-sgp-enap/sedgg/me-n-21-de-1-de-fevereiro-de-2021-302021570.

Lei n. 8.112, de 11 de dezembro de 1990. Dispõe sobre o regime jurídico dos servidores públicos civis da União, das autarquias e das fundações públicas federais. Diário Oficial [da] República Federativa do Brasil, http://www.planalto.gov.br/ccivil_03/leis/18112cons.htm.

Lei n. 9.394, de 20 de dezembro de 1996. Estabelece as diretrizes e bases da educação nacional. Diário Oficial [da] República Federativa do Brasil, http://www.planalto.gov.br/ccivil_03/leis/19394.htm.

Lei n. 12.772, de 28 de dezembro de 2012. Dispõe sobre a estruturação do Plano de Carreiras e Cargos de Magistério Federal; sobre a Carreira do Magistério Superior, de que trata a Lei n. 7.596, de 10 de abril de 1987; sobre o Plano de Carreira e Cargos de Magistério do Ensino Básico, Técnico e Tecnológico e sobre o Plano de Carreiras de Magistério do Ensino Básico Federal, de que trata a Lei n. 11.784, de 22 de setembro de 2008; sobre a contratação de professores substitutos, visitantes e estrangeiros, de que trata a Lei n. 8.745 de 9 de dezembro de 1993; sobre a remuneração das Carreiras e Planos Especiais do Instituto Nacional de Estudos e Pesquisas Educacionais Anísio Teixeira e do Fundo Nacional de Desenvolvimento da Educação, de que trata a Lei n. 11.357, de 19 de outubro de 2006; altera remuneração do Plano de Cargos Técnico-Administrativos em Educação; altera as Leis n.s 8.745, de 9 de dezembro de 1993, 11.784, de 22 de setembro de 2008, 11.091, de 12 de janeiro de 2005, 11.892, de 29 de dezembro de 2008, 11.357, de 19 de outubro de 2006, 11.344, de 8 de setembro de 2006, 12.702, de 7 de agosto de 2012, e 8.168, de 16 de janeiro de 1991; revoga o art. $4^{\circ}$ da Lei n. 12.677, de 25 de junho de 2012; e dá outras providências. Diário Oficial [da] República Federativa do Brasil, http://www.planalto.gov.br/ccivil_03/_ato2011-2014/2012/lei/112772.htm.

Luchesi, E. S. F. (2012). Gestão do Conhecimento nas Organizações. Companhia de Engenharia de Tráfego CEF-SP, Nota técnica n. 221/2012. https://www.academia.edu/10808311/GEST\%C3\%83O_DO_CONHECIMENTO_NAS_ORGANIZA\%C3\%87\%C3\%95ES?email_work_card=title.

Martins, P. B., Ribeiro, G. L. F., \& Carvalho, J. G. (2017). Contribuições das Comunidades de Prática para o Treinamento e Desenvolvimento de Pessoas. Research, Society and Development, 4(4), 239-250. https://doi.org/10.17648/rsd-v4i4.7

Oliveira, J. A., \& Medeiros, M. P. M. (2016). PNAP - Bacharelado - Gestão Pessoas Setor Público. http://educapes.capes.gov.br/handle/capes/145368.

Pereira A. S. et al. (2018). Metodologia da Pesquisa Científica. p. 119. https://repositorio.ufsm.br/bitstream/handle/1/15824/Lic_Computac ao_MetodologiaPesquisa-Cientifica.pdf?sequence $=1$.

Resolução n. ${ }^{\circ}$ 031, de 23 de setembro de 2011, do Conselho Superior (CONSUP) do Instituto Federal de Mato Grosso. Regulamenta o Programa de Avaliação de Desempenho dos Servidores Técnico-Administrativos em Educação do Instituto Federal de Educação, Ciência e Tecnologia de Mato Grosso. http://ifmt.edu.br/media/filer_public/5f/f0/5ff04b5c-b48b-49a4-b211-499a1cc6946e/resolucao-no-0312011-aprovar-programa-de-avaliacao-desempenho-dostecadm_merged.pdf.

Resolução n. ${ }^{\circ} 510$ de abril de 2016. Ministério da Saúde. Conselho Nacional de Saúde. Dispõe sobre as normas aplicáveis a pesquisas em Ciências Humanas e Sociais cujos procedimentos metodológicos envolvam a utilização de dados diretamente obtidos com os participantes ou de informações identificáveis ou que possam acarretar riscos maiores do que os existentes na vida cotidiana, na forma definida nesta Resolução. Diário Oficial [da] República Federativa do Brasil, http://conselho.saude.gov.br/resolucoes/2016/Reso510.pdf.

Resolução n. ${ }^{\circ}$ 047, de 21 de novembro de 2019, do Conselho Superior (CONSUP), do Instituto Federal de Mato Grosso. Este Regulamento trata da Política de Desenvolvimento e Capacitação de Pessoas do Instituto Federal de Educação, Ciência e Tecnologia de Mato Grosso - IFMT e encontra-se consubstanciado nos termos da Lei n. 8.112, de 11/12/1990; da Lei n. 9.394, de 20/12/1996; da Lei n. 9.527, de 10/12/1997; da Lei imbernónn. 11.907, de 02/02/2009; do Decreto n. 7.312, de 22/12/2010; do Decreto n. 5.824, de 29/06/2006; da Lei n. 11.091, de 12/01/2005; da Lei n. 12.772, de 28/12/2012; do Decreto n. 9.991, de 28/08/2019, e demais normas vigentes. http://ifmt.edu.br/media/filer_public/46/2008c9/46c96160-1b22-422f-9ef7-1897dfc3bbd4/resolucao_no_047__21112019_-_aprovar_-_ad_ref_-_regulamento_da_politica_de_desenvolvimento_e_capacitacao_de_pessoas.pdf.

Silva, C. M. B., \& dos Santos, E. O. (2020). Formação continuada do professor do ensino médio integrado: concepções e importância. Revista Brasileira da Educação Profissional e Tecnológica, 1(18), 9281. http://www2.ifrn.edu.br/ojs/index.php/RBEPT/article/viewFile/9281/pdf.

Strauhs, F. D. R., Pietrovski, E. F., Santos, G. D., Carvalho, H. G. D., Pimenta, R. B., \& Penteado, R. D. F. S. (2012). Gestão do conhecimento nas organizações. http://repositorio.utfpr.edu.br/jspui/bitstream/1/2064/1/gestaoconhecimentoorganizacoes.pdf.

Tocantins, J. B. (2018). Gestão por competências como base para o planejamento da força de trabalho em uma instituição pública de ensino superior. Dissertação de mestrado. https://repositorio.unesp.br/bitstream/handle/11449/166419/tocantins_jb_me_guara.pdf?sequence=3\&isAllowed=y.

Vieira, J. G. S. (2010). Metodologia de pesquisa científica na prática. Editora Fael. 